\title{
Significações Dadas pelos Progenitores acerca do Diagnóstico de Câncer dos Filhos
}

Meanings Given by the Parents of Children Diagnosed with Cancer

Significaciones Atribuidas por los Padres sobre el Diagnóstico de Cáncer de sus Hijos

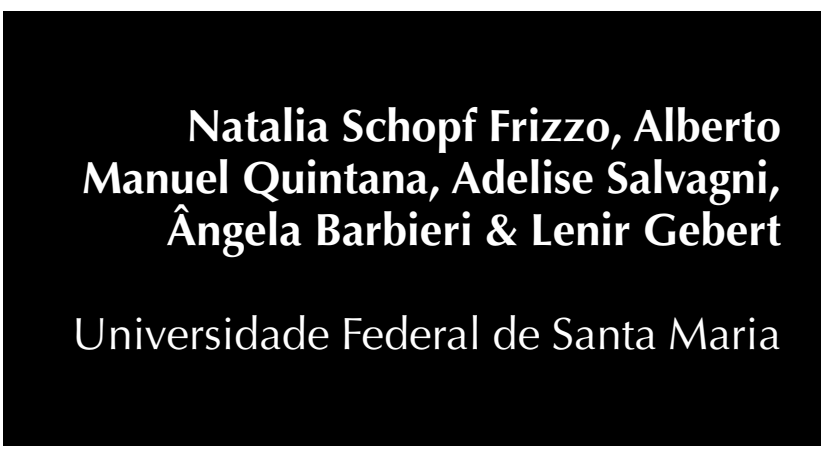

http://dx.doi.org/10.1590/1982-3703001772013 
Resumo: Este trabalho teve como objetivo compreender as significações atribuídas pelos pais acerca do diagnóstico de câncer de seus filhos. Os dados foram coletados por meio de entrevistas semiestruturadas, com sete progenitores de crianças acometidas por câncer que estavam em tratamento em um hospital público do Rio Grande do Sul. Os dados foram interpretados através da análise de conteúdo, a qual permitiu a elaboração de cinco categorias, a saber, Da suspeita do diagnóstico ao choque da confirmação, "A vida da gente para, né", A família que "adoece junto": repercussões e adaptações familiares mediante o diagnóstico As culpas, as faltas e as dores: os significados dados pelos pais para a doença acometida aos filhos, Mudanças físicas e emocionais: a compreensão de sua doença pela criança e a "preocupação natural" dos pais e Perspectivas para o futuro. Concluiu-se que profundas ressonâncias familiares são suscitadas pela enfermidade que acomete o infante e os significados dados à doença confirmam o processo do tratamento como sendo fonte de tensão, rompimentos profissionais e sociais, sofrimento e estresse elevado para toda a família.

Palavras-chave: Psicologia. Oncologia. Pediatria. Diagnóstico.

Abstract: This study aimed to understand the meanings attributed by parents regarding the cancer diagnosis of their children. Data were collected through semi-structured interviews with seven parents of children affected by cancer who were being treated in a public hospital in Rio Grande do Sul, Brazil. The data were interpreted by using content analysis, which allowed the creation of five categories, namely 1) the shock suspected diagnosis confirmation: "our lives stops, right?; The family "sicken together"; 2 ) the impacts and adaptations of the family during the diagnosis: the guilt, absence, and pain; 3) the meanings given by parents to the disease that affect their children; physical and emotional changes; 4) child's understanding of their illness and the "natural concern" of parents; and 5) prospects for the future. It was concluded that deep implications are raised by the family disease that affects the infant and the meanings given to illness confirm the treatment process as a cause of voltage source, professional and social disruptions, distress, and high stress for the entire family.

Keywords: Psychology. Medical Oncology. Pediatrics. Diagnosis.

Resumen: Este trabajo tuvo el objetivo de comprender las significaciones atribuidas por los padres sobre el diagnóstico de cáncer de sus hijos. Los datos fueron colectados por medio de entrevistas semi-estructuradas, con siete progenitores de niños acometidos por cáncer que estaban en tratamiento en un hospital público del Rio Grande del Sur, Brasil. Los datos fueron interpretados a través del análisis de contenido, el cual permitió la elaboración de cinco categorías, a saber; De la sospecha del diagnóstico al choque de la confirmación, "La vida de uno para", La familia que "enferma junto a los hijos": repercusiones y adaptaciones familiares mediante el diagnóstico, Las culpas, las faltas y los dolores: los significados dados por los padres a la enfermedad de sus hijos, Cambios físicos y emocionales: la comprensión del niño de su propia enfermedad y la "preocupación natural" de los padres y Perspectivas para el futuro. Se concluyó que profundas resonancias familiares son generadas por la enfermedad que ataca al infante y los significados dados a la misma confirman el proceso de tratamiento como siendo fuente de tensión, rupturas profesionales y sociales, sufrimiento y estrés profundo para toda la familia.

Palabras clave: Psicología. Oncología Médica. Pediatría. Diagnóstico. 


\section{Introdução}

A enfermidade implica certa condição de vida que interroga a saúde. Nesse contexto, embora o imaginário contemporâneo rechace as experiências de sofrimento, o processo da vida abarca, pois, a doença e a presença da morte. Nesse sentido, a construção do homem enquanto sujeito perpassa pela inclusão das noções de vida e de morte como valores e as relações entre doente, doença se instituem, assim, na rede histórica das concretudes do existir humano (Teixeira, 2006). Contudo, o adoecer é, muitas vezes, percebido como desventura, infelicidade, como desmantelador do processo vital. A patologia, ainda, é colocada no campo do excesso, do sofrimento e da paixão que se estabelecem sobre o homem e demandam dele passividade, modificando sua natureza (Berlinck, 2000).

Quando se fala, pois, de uma doença grave, como um câncer, a ameaça da perda do filho, objeto de amor, faz com que o luto se estabeleça desde o momento em que os pais tomam conhecimento da doença. Esse luto, conforme dado por Freud (1916/1996), estabelece-se como parte da reação sadia frente ao adoecimento sendo, portanto, direito dos pais e, também, da criança receber informações sobre seu diagnóstico e terapêutica, no momento propício, de acordo com a idade e nível de compreensão (Valle, 1997).

O luto também pode referir-se à profissão na qual a mãe vai deixar de atuar, a fim de acompanhar a criança nas consultas médicas, ao papel do pai que vai ser alterado, incluindo atividades distintas que antes não Ihe competiam, ao abandono do ambiente familiar em detrimento dos longos períodos em clínicas ou hospitais, à perda da rotina infantil, ao distanciamento da escola, das brincadeiras com os amigos e, inclusive, ao luto pelo corpo infantil, que vai sofrer modificações em virtude da radioterapia ou quimioterapia. Portanto, os sentimentos que os familiares experimentam após o anúncio do diagnóstico do câncer aludem não só à probabilidade de uma morte física, mas também faz menção às várias modificações estruturais que a doença e o tratamento implicam na vida do filho (Souza, Lemos, Maia, Marques, \& Silva, 2010).

O câncer confronta o indivíduo às questões da morte, da castração. De fato, o diagnóstico coloca em xeque a organização subjetiva, processo ressaltado pelo "estigma do câncer como uma doença fatal" (Quintana, 1999, p. 107). Essa correlação linear entre câncer e morte recai sobre o indivíduo, deixando-o em uma situação de abandono, de sentimentos de solidão e de carência de afeição que se assemelha à condição de trauma psíquico descrita por Freud (1937/1976).

Santos e Sebastiani (2003) acrescentam que o fator mais crucial que levaria a um desajuste psicossocial na criança enferma é, possivelmente, o modo como a família funciona e é capaz de adaptar-se à doença da criança. Assim, entende-se que a maneira com a qual o trauma é elaborado e vivenciado pelos pais dirá da maneira com a qual o será pelos filhos. A perda de um objeto de amor e de investimentos será acompanhada de um trauma e, portanto, o câncer, sendo potencializador de perdas significativas presentes física e psiquicamente, caracteriza-se por um estigma de fatalidade e sofrimento contínuos. Compreender as significações dadas pelos pais à doença que acomete esse corpo - o do seu filho - é criar elementos para a elaboração da mesma e reconhecer, nesse processo, as muitas implicações sociais e psicológicas do câncer infantil que podem até mesmo ser mais cansativas do que a própria doença física (Patistea, 2005).

\section{Método}

É um estudo descritivo e exploratório, de cunho qualitativo. Turato (2003) refere que a abordagem qualitativa possibilita o entendimento do significado que as pessoas atribuem a determinado fenômeno, e percebe-se esta abordagem como adequada para este estudo.

A pesquisa teve como cenário o setor de tratamento de câncer infanto-juvenil de um hospital público do Rio Grande do Sul. Para a realização da coleta de dados, 
foram utilizadas entrevistas semiestruturadas, guiadas através de eixos norteadores. Tais entrevistas, conforme Minayo (2008), partem da elaboração de um roteiro, que difere do sentido tradicional do questionário, pois objetiva apreender o ponto de vista dos atores sociais previstos no objetivo da pesquisa. $\mathrm{O}$ roteiro conta, portanto, apenas com alguns itens que se tornam indispensáveis para o delineamento do objeto, constituindo-se, pois, como um guia, não havendo perguntas estruturadas e não podendo prever todas as situações e condições de trabalho em campo. Tais itens, que constituíram os eixos norteadores desta pesquisa, foram os seguintes: A suspeita da doença, O momento da notícia do diagnóstico, O histórico do tratamento e os procedimentos atuais, A vida social e profissional a partir do diagnóstico da enfermidade, A vida familiar a partir do diagnóstico da enfermidade, $\mathrm{O}$ impacto da doença na criança, temores e fantasias e expectativas em relação ao futuro.

A proposta abarcou sete progenitores de crianças atendidas no setor proposto inicialmente. Estas entrevistas foram realizadas individualmente com cada sujeito da pesquisa, sendo as mesmas gravadas, posteriormente transcritas e analisadas. A fim de manter o anonimato dos sujeitos da pesquisa, os nomes foram substituídos por um código - tendo sido utilizado letras aleatórias distintas daquelas iniciais dos nomes originais, as quais são acompanhadas pela letra $M$, indicando masculino/pai e F, indicando feminino/mãe. Os sujeitos entrevistados dividiram-se em seis mulheres e um homem, cuja escolaridade variava entre segundo grau incompleto a nível superior completo. As idades situavam-se entre 30 e 55 anos e as profissões relatadas foram enfermagem, dona de casa, trabalho no campo, taxista e autônomo.

O número de entrevistas foi determinado pela saturação da amostra. Tal conceito consiste, segundo Minayo (2008), no conhecimento obtido pelo pesquisador de que apreendeu a lógica interna do grupo pesquisado. Este momento ocorre quando o mesmo alcança o entendimento da homogeneidade, da diversidade e da intensidade das informações necessárias para o estudo. A amostra foi, pois, saturada após a realização de sete entrevistas, incorporadas em um processo contínuo de análise de dados o qual se iniciou juntamente com o processo de coleta.

Após a realização das entrevistas, os dados foram examinados através da análise de conteúdo. Tal método de consideração refere-se a uma forma de tratamento e análise das informações de discursos pronunciados, não só oralmente como por gestos, figurações e imagens, ou seja, pelo que está por detrás das palavras. Segundo Campos (2004), a análise de conteúdo é um conjunto de técnicas de pesquisa cujo objetivo é a busca do sentido ou dos sentidos de um documento.

Conforme orienta Turato (2003), para o tratamento e análise dos dados, após a transcrição do material, foi realizada a leitura flutuante até a impregnação do conteúdo. Com base em critérios de relevância e repetição, foram identificados temas emergentes. Para tal, foram considerados tanto os aspectos que se repetiam, comuns aos entrevistados, como os relevantes, que não necessariamente se repetiram, mas que foram considerados ricos em conteúdo. A partir destes temas, realizou-se a categorização dos tópicos emergentes das falas.

Salienta-se que, em todas as etapas da pesquisa, foram considerados os aspectos éticos. Os sujeitos da pesquisa receberam esclarecimentos sobre a pesquisa e suas implicações, de forma que, antes da realização das entrevistas, receberam o termo de consentimento livre e esclarecido, o qual autorizou sua participação na pesquisa. $\mathrm{O}$ projeto da pesquisa foi aprovado pelo Comitê de Ética (CAAE 05148012.2.0000.5346).

\section{Resultados e discussão}

A partir da análise das entrevistas, algumas questões emergiram como categorias relevantes para a compreensão das significações dadas pelos pais acerca do diagnóstico de câncer de seus filhos. Em torno dessas temáticas, serão desenvolvidas algumas considerações a seguir. 
Da suspeita do diagnóstico ao choque da confirmação

Compreende-se por doença o desacordo orgânico ou psíquico que produz uma ruptura na dinâmica do desenvolvimento do indivíduo, desarmonizando-o enquanto pessoa. Juntamente com o abalo estrutural na condição de ser dentro da sua sociocultura, a doença propicia um rompimento na dinâmica e nas relações entre o indivíduo consigo mesmo e com o mundo (Santos, \& Sebastiani, 2003). Nesse sentido, entende-se que o processo de adoecer envolve uma multiplicidade de fenômenos para além do físico, ou seja, o ser doente tem de enfrentar os sintomas que acometem a dor corporal e lutar contra as dificuldades emocionais em confrontar e aceitar/aceitar-se limitado pela doença.

Por sua vez, o câncer repercute como uma doença impregnada de significados pejorativos, experienciada ainda como uma fatalidade que suprime a possibilidade de um amanhã (Mazzora, \& Tinoco, 2005). Dessa forma, a palavra câncer vem assinalada, como se pode perceber nas falas a seguir, como sinônimo de maldição, algo deveras impronunciável e incabível no seio familiar:

"Câncer é uma doença maldita" (KF).

“Às vezes a gente falava câncer isso aí até hoje não me convenci que minha filha tem isso, é uma palavra muito [...] não da pra ti ler ou falar essa palavra, eu nunca falo que minha filha tem câncer" (XF).

Assinala-se, portanto, que a doença é sentida pelo indivíduo, como uma agressão, gerando um abalo na condição de ser, tornando o futuro incerto. Instalando-se de maneira abrupta, a doença não permite ao sujeito uma adaptação gradativa à facticidade (Santos, \& Sebastiani, 2003). Ainda, cabe ressaltar que ninguém está preparado para adoecer e/ou seguro e confiante o bastante para lidar com a doença na hora imediata em que ela aparece.

"Foi tão rápido assim, uma coisa tão surpreendente, sabe assim, nunca teve dor [...] ele nunca teve sintoma nenhum" (KF).
"Ele não tinha nada, o máximo que ele teve foi infecção na garganta, ele não tinha dificuldade em nada [...], de repente tu descobre que ele tem leucemia" (QF).

Mediante a surpresa do diagnóstico grave, o despreparo para lidar com o surgimento deste na infância - já que se espera que a criança esteja no "início da vida", em plena atividade - a existência gira agora em função da doença e o mundo acaba por tornar-se, em muitos casos, vazio, desinteressante e pobre. Tal incursão do estado doente na vida familiar acaba por gerar intenso desprazer causado pelos instrumentos, pelo ambiente agora vivenciado - o hospital, pelas dores no corpo que tendem a fazer "doer à alma". As privações de intimidade, individualidade e a ausência de prazer corporal acarretam perdas profundas ao indivíduo doente, muitas vezes equivalentes as perdas de um objeto de amor e acarretam as mesmas reações de luto (Santos, \& Sebastiani, 2003).

“... brabo, brabo mesmo foi quando teve que amputar a perna [...], foi aí que eu caí numa depressão bem profunda" (WF).

É importante salientar, também, que as primeiras manifestações visíveis da doença na criança tendem a ser através de sintomas amenos que levam a crer na possibilidade de diversos diagnósticos diferentes, o que pode excluir o câncer como possibilidade primária. Nesse sentido, o diagnóstico precoce é geralmente complicado de se obter quando se trata de crianças, uma vez que, a progressão da doença é silenciosa desde o início e, portanto, seus sinais e sintomas tendem a aparecer somente quando a mesma já está avançada (Marques, 2004). Contudo, essa demora em nomear adequadamente $\mathrm{o}$ diagnóstico específico faz, muitas vezes, com que o tratamento atrase, trazendo angústia e sofrimento prolongados:

\footnotetext{
"Apareceu mancha roxa na canela, e daí vimos aquilo ali e não dava muita bola, sabe [...] aí começou a aparecer na cabeça, assim, mancha, caroço, e mancha aí fizemos o exame de urina tudo, e aí no outro dia saiu que era câncer mesmo" (UM).
} 
"Ele torceu o joelho dele sabe jogando futebol, né, dali inchou um pouquinho, medicou pra dor, aí, do nada assim inchou o outro pé, aí já inchou o joelhinho dele, daí no dia que ele foi consultar no médico [...] internaram ele pra fazer exame de sangue. Aí nos não sabia o certo, daí diagnosticaram né, leucemia" (Y).

Todavia, vale ressaltar que o diagnóstico em si da doença desencadeia reações de choque entre os membros da família. Os pais sofrem intensamente com o descobrimento do câncer na criança e este momento tende a ser vivenciado "como um tempo de catástrofe e de incertezas" (Valle, 1994, p. 220). Desde o momento em que o câncer é comunicado, "profundas alterações nela ocorrem e isto afeta não só seus membros, mas também pessoas do seu círculo de relações" (Lima, 1995, p. 89). Ainda, compreende-se que já no momento da comunicação do diagnóstico inicia-se, para a família, o processo de perda do ente querido, trazendo "o temor da possibilidade da morte" e, portanto, um processo de luto antecipatório (Parkes, 1998). Assim, os processos de sofrimento podem ser observados nas falas a seguir:

"Foi um desespero total, não tem notícia pior [...], é como se me passou uma paulada e eu não consegui levantar" (KF).

"Foi um choque, né a gente nem esperava, uma criança super sadia, super ativa, sabe, do nada assim" (YF).

Ocupando, então, um espaço de temor e desempenhando o papel de enfermidade cruel e devastadora, para muitos o diagnóstico do câncer significa uma sentença de morte (Valle, 1997). Essa situação acaba por levar os familiares a experienciar estados de confusão diante de inúmeras situações inesperadas, como o acúmulo de informação que lhes é transmitida assim que chegam, e/ou a vivência de ocasiões desagradáveis, desencadeadas, entre outros fatores, por presenciarem cenas de sofrimento no dia a dia do hospital. Portanto, o temor da família permite que a mesma reaja de maneira ambígua, querendo saber o que o filho tem, mas por outro lado, negando a doença em si por ter dificuldade de enfrentar a realidade que se antevê (Crepaldi, 1998), conforme explanam os pais nas falas sequentes:

"A ficha foi caindo aos poucos, e, às vezes, eu dormia achando que era um sonho e quando eu acordava via que aquilo tudo era realidade" (QF).

"Ah, não da nem pra falar né, às vezes a gente fica olhando tudo que acontece, no começo daí, primeiro dia fui pro corredor e falei pra doutora 'não to bem', né" (U).

Entretanto, é imprescindível ressaltar que o modo de enfrentamento da enfermidade passa pela forma com a qual os indivíduos de uma dada sociedade se situam perante a essa, visto que os mesmos sintomas ou doenças tendem a ser interpretados de diferentes maneiras em distintas situações e culturas (Beck, \& Lopes, 2007). Acresce-se a este contexto que os níveis intrapsíquico, interpessoal e social de uma família afetarão as respostas de outros membros e vice-versa, num movimento compensatório (Santos, \& Sebastiani, 2003). Nesse sentido, considera-se necessário compreender que cada membro da família elaborará o processo de doença de maneira particular. É a família como um todo, ou todos aqueles que estiverem imbuídos desse processo de cuidar que estarão responsabilizados a facilitar a elaboração de sua doença por parte da criança e, portanto, é o diálogo claro e constante que colabora para o entendimento da criança sobre o que se passa com ela. Contudo, os relatos dados pelos pais foram contrários com a necessidade e importância de se falar sobre a doença com a criança:

"Eu procuro não falar muito disso na frente dele, pra poupar ele também né. É o suficiente pra ele saber que ele tem que se tratar, mas ele não precisa saber mais pra ele não sofrer também" (QF).

Concomitante, Castro e Piccinini (2002) também relatam que a aceitação da doença pela criança está ligada à aceitação por parte daqueles que a cuidam. Os recursos psicológicos dos genitores, da própria criança e a estrutura familiar interagem e, portanto, podem contribuir para a adaptação da criança à doença. Sendo assim, entende-se que o 
câncer infantil se constitui em uma doença que acomete a todos, paciente e cuidadores. Os ataques físicos, psíquicos, sociais sofridos repercutem na criança e família, fonte de cuidado e responsável pela apresentação do mundo à criança. O que um compreende desses episódios reflete diretamente na forma de aceitação e compreensão do outro. Ou seja, todo o processo de adoecimento e cura por parte da criança está permeado pela condução, interpretação, compreensão dos pais acerca de tal vivência (Cardoso, 2007).

"A vida da gente para, né?"

Compreendendo-se a doença enquanto fenômeno de dimensão social e o indivíduo doente como parte de uma sociedade fomentadora de saberes, entende-se as interações sociais como papel de destaque na compreensão dos cuidados de saúde adotados no cotidiano (Beck, \& Lopes, 2007). Partindo-se, portanto, dessa premissa, a percepção de doença pela criança tende, pois, a se constituir a partir de tudo que vivenciou até o momento, e depende de como a sua família compreende e explica o processo de adoecer. Entretanto, mediante o processo de significação da doença pelos pais, as alterações no convívio e representações sociais acabam por interferir na compreensão do adoecimento do infante. Isso vai ao encontro dos apontamentos de Valle (2001) quando esta acrescenta a perda do mundo habitual, anteriormente vivido, em decorrência da doença que se estabeleceu como algo frequente nos casos de pais de crianças com doenças crônicas. Assim, os relatos obtidos nas entrevistas realizadas refletem o sentimento de desordem imposta pelas alterações sociais vivenciadas a partir do diagnóstico da doença:

"Abala tudo, né, mulher, principalmente a família da gente, tu trabalhava pra fora e agora não pode trabalhar mais, meu marido coitado também trabalha, tem que cuidar da casa, a gente passa mais viajando" (KF).

"Tô afastada do meu trabalho, né, é bem complicado [...] falei um pouco com a minha chefe, então assim ela não tá me passando `ah, fica tranquila`, sabe ela não fala, eu sinto assim por parte dela uma certa cobrança" (Q).

Mediante os relatos, foram observados sentimentos de solidão e isolamento que se atrelam a ambivalências - permanência e transitoriedade, poder e impotência, vida e morte - determinadas pelo processo de adoecer (Santos, \& Sebastiani, 2003). Ainda destaca-se o afloramento de sentimentos que surgem para os pais que convivem com a doença dos filhos, tais como a insegurança diante do futuro da criança, o aumento do estresse, a raiva, o ressentimento como reação em face da doença e da finitude. Tais sensações tendem a surgir em famílias que compreendem o significado do processo existencial, acompanhadas, ainda, e de forma ambivalente, de estratégias de enfrentamento e manifestação de sentimentos de esperança assumidos frente à morte e o morrer da criança (Silva, Weiss, Bernardes, \& Souza, 2006).

A hospitalização aparece como destaque no processo do adoecer e na significação dos pais acerca da doença de seu filho. A desorganização das rotinas, o sofrimento que vivencia a desestruturação do cotidiano familiar, as responsabilidades domésticas que são abandonadas e as demandas financeiras da hospitalização são aspectos que interferem diretamente na vivência da doença. Tais fatos experienciados associados ao significado de se ter um filho doente e hospitalizado levam ao limiar de anseios, atos e pensamentos que refletem a dificuldade para lidar com a situação (Silva, Andrade, Barbosa, Hoffmann \& Macedo, 2009), tal qual pode ser observado nos excertos abaixo:
"Ah, eu tive que parar com tudo, minha vida social mudou muito também, por- que daí assim tem que se dedicar mais a ele, né, 24 horas por dia praticamente, $n e^{\prime \prime}(\mathrm{WF})$.
"Ah, tudo muda né, tudo, não tem como a gente continuar uma vida normal, né, tem muitas coisas que eu tive que parar de fazer por causa disso, né" (Z).

Dessa forma, evidencia-se que, na medida em que as crianças iniciam e prosseguem com o 
tratamento, por sua vez, a necessidade de um acompanhante contínuo se faz fundamental, é comum que um dos pais, ao menos, tenha de abrir mão de seu trabalho, da vida social, da casa. O lar étrocado pelo hospital e a dedicação se torna exclusiva daquele filho adoentado. A vida toma novos rumos, novos amigos são feitos no ambiente vivido em que dores são compartilhadas e reconhecidas, os longos períodos de internação fazem dos tratamentos e acompanhamentos as novas tarefas de vida dos pais. Assim, a vida social, de um modo geral, é substituída por constantes visitas ao médico, sendo necessário que os pais permaneçam atentos às medicações e hospitalizações da criança. Como consequência disso, todos aqueles que convivem com o doente acabam sendo atingidos (Castro, \& Piccinini, 2002).

A família que "adoece junto": repercussões e adaptações familiares mediante o diagnóstico

As famílias, tais quais os filhos enfermos, normalmente, passam por diferentes estágios que envolvem o momento inicial de choque e negação, segue-se de raiva e ressentimento e adentra, posteriormente, em um estágio permeado pela culpa e sentimentos para com o paciente. Após tais períodos, a família dirigese para o estágio de tristeza (depressão) até alcançar a condição de aceitação. Entretanto, além do conflito singular de cada membro familiar diante do adoecer, a família tem de enfrentar o problema da criança enquanto incapacitada e fragilizada. Tais exigências repercutem na dificuldade e agravamento dos remanejamentos de cargas afetivas, imprescindíveis para manter a estrutura familiar neste momento crítico (Santos, \& Sebastiani, 2003), conforme salientam as falas abaixo:

"Foi bem puxado, porque a gente tinha os pequenininhos lá, né, sou de longe onde que moro, né, já tinha outros filhos, o pequeno mamava no peito ainda quando eu vim pra cá, aí era dividido, né" (YF).

Não há estabilidade no tratamento oncológico: há dias em que a criança está bem e há outros em que mostra piora expressiva, e é necessário lidar com isso. Assim, constata-se maior dificuldade entre os familiares para dar o suporte de que o paciente precisa, pois esses também se fragilizam, como no excerto abaixo:

"A gente sempre ouve falar de câncer, né, então todo mundo ficou assim [...], um choque né, mas ninguém tipo assim desatou por causa disso, né" (ZF).

Contudo, o modo como a família recebe o diagnóstico também poderá intervir positiva ou negativamente na aceitação que o paciente terá do tratamento (Silva, 2000; Pedrosa, Pedrosa, Pedrosa, \& Pedrosa, 2005), já que, segundo Penna (2004), as famílias desempenham grande influência sobre o rumo da doença no paciente, especialmente quando este é uma criança. Se bem orientadas, poderão ampará-la na utilização de seus recursos de adaptação de forma mais eficaz, respeitando suas possibilidades e limitações individuais.

Dessa forma, pode-se pensar que não só a criança se torna vítima do câncer, mas também sua família (Valle, 2001). Nesse sentido, Penna (2004) sugere que, assim como existem distintos tipos de câncer, também existem diferentes tipos de famílias. Por sua vez, esse diagnóstico ocasionará consequências particulares em cada uma delas (Carter, \& McGoldrick, 2001).

As culpas, as faltas e as dores: os significados dados pelos pais para a doença acometida aos filhos

As significações perante o adoecer sofrem também influências de um processo de culpa que acompanha os pais diante ao diagnóstico do câncer. Diversas famílias sentem-se culpadas por, de fato, crerem ter sido as causadoras da grave doença em seu filho. Kovács (1992), nesse sentido, acrescenta que a culpa relaciona-se à noção de castigo, e, portanto, não seria estranho que, então, se procure este para aliviar aquela. Assim, na tentativa de algo que alivie seu sofrimento e o da criança, a família encontra nas tentativas de compensações, terreno fértil dada à própria fragilidade atribuída pela angústia do período traumático, como se pode perceber no seguinte depoimento: 
"Agora a gente procura dar mais atenção do que puder, o meu objetivo agora é só ele, eu larguei de mão tudo e agora meu objetivo é só ele" (KF).

"Eu espero compensar as perdas que ele teve e eu espero assim que ele seja feliz" (Q).

Os significados dados à doença revelam-se, então, perpassados por ausências e carências que dificultam a convivência com ela e sua compreensão. Entretanto, para o entendimento desse processo de significação da doença, é importante considerar que, desde antes de nascer, a criança já é depositária de uma série de expectativas, tanto do casal quanto das famílias de origem (Silva, 2000). Um filho representa a capacidade criadora dos pais (Lacaz, 2003), a possibilidade de imortalidade, na medida em que ele é a continuação do casal (Casellato, 2002); por isso, instala-se um grande paradoxo no caso das crianças enfermas, pois a dor de constatar que o filho real (com câncer) é diferente do filho imaginado (saudável) deixa profundas marcas no narcisismo dos pais.

Com o surgimento da doença, portanto, todo o sentido de futuro passa a ser ameaçado, e a família depara-se repentinamente com a possibilidade da perda, de dor e de sofrimento e também com a frustração de não ver concretizados seus anseios (Lacaz, 2003; Ramalho, 2002). Assim, um grande esforço delineado pela dedicação intensa e foco na cura da doença do filho passa a servir de meta a esses pais na tentativa de reaver-se com seu narcisismo e com a "des'culpabilização" que a doença crônica impõe a eles:

"O meu objetivo agora é só tratar de curar ele [...], aí depois a gente vê o que faz [...]. Fazer planos eu não posso [...], o futuro a Deus pertence" (KF).

Mudanças físicas e emocionais: a compreensão de sua doença pela criança e a "preocupação natural" dos pais

O câncer é um desconhecido que penetra a privacidade familiar chegando sem pedir licença e coloca as pessoas diante de situações com as quais não sabem lidar. Quando a doença crônica acomete crianças, entende-se esta como um estressor que afeta o desenvolvimento infantil e atinge as relações sociais dentro do sistema familiar (Castro, \& Piccinini, 2002). Chiattone (2003) afirma que o afastamento do ambiente doméstico e escolar, em função de longos períodos de internação, provoca, em muitos casos, a desorganização do mundo interno da criança e de seus cuidadores. Devido a todas as novidades inseridas no seu cotidiano (medicamentos, exames, consultas e diversos procedimentos invasivos), o pequeno paciente experiencia novas sensações tais como medo, sensação de punição, despersonalização, regressão no seu desenvolvimento psicológico e cognitivo (Angerami-Camon, 1997; Chiattone, 2003), o que leva os pais a sentirem-se, muitas vezes, despreparados para lidar com o próprio filho:

"Ela [a criança enferma] ficou bastante nervosa, no começo bastante, até pra falar ela falava fanho, ela não mastigava direito, era muito difícil" (X).

Quando se aborda o infantil, nos cabe partir da ideia de que a noção de eu (e de corpo, por sua vez) surge da interação e investimento libidinal por parte daqueles que fazem os papéis de pai e mãe. É esse mesmo corpo que sofrerá pela dor e intervenções do tratamento e, portanto, é a partir de tal relação parental que a subjetividade do indivíduo se mobilizará a fim de compreender e lutar contra a doença. Nesse sentido, Freud (1923/1990) explica que esse corpo representa o terreno sobre o qual se constrói a relação com o outro parental, relação essa primordial e constitutiva da subjetividade.

Assim, torna-se fundamental que a família desenvolva a capacidade de ser continente, de acolher e lidar com as dores que aparecem na trajetória do tratamento já que, conforme Vieira e Lima (2002), as mudanças físicas, de ambiente e até de tratamento por parte de seus familiares permitem que a criança tenha uma percepção clara de que a doença está Ihe acometendo e sobre as mudanças pelas quais tem de passar. Tais mudanças físicas ocorridas em função do tratamento oncológico repercutem, por sua vez, lado a lado às emocionais. O que se vê, as alterações, 
as marcas da doença constituem-se como comprovação da mesma. O estar de cama, o enfraquecimento, os cabelos que caem, a imunidade que baixa, tudo contribui para que se altere a rotina, os interesses, a disposição. A criança sente que está mudada, os pais sentem as mudanças das mesmas e ambos sofrem. A doença realmente chegou, está ali, bem na frente, aparecendo:

"Caiu o cabelinho, quando vi a imagem eu chorei, sabe [...], porque foi aí que se confirmou pra mim a doença dele" (QF).

Mesmo diante dos conflitos de ideias, imaginações, sentimentos e significados e em meio às percepções e experiências em situações delicadas, a criança, algumas vezes, constrói uma imagem particular a respeito da doença. Dessa forma, questões referentes a esse assunto são inquietantes para ela, pois, na qualidade de "criança doente", indagase sobre seu próprio acometimento. Para a criança, o acometimento pelo câncer é permeado por sentimentos múltiplos suscitados frente a toda problemática que abarca o "estar doente" e o "fazer tratamento", o que colabora para engrandecer a importância da comunicação dos pais com a criança sobre sua doença (Cagnin, Liston, \& Dupas, 2004).

Além disso, enfrentar a desintegração de sua identidade frente às alterações corporais decorrentes da debilitação da doença e dos efeitos adversos do tratamento faz com que sua autoestima fique comprometida. Percebendo, pois, que sua doença interfere consideravelmente no ritmo familiar, o processo de culpa pela própria doença tende, muitas vezes, a se estabelecer na criança. Os pais passam a ser depositários do ódio e do amor da criança. Ódio pelas ausências, fantasias agressivas originadas pela doença e afeto, uma vez que os pais constituem-se objetos de amor para a criança (Santos, \& Sebastiani, 2003):

“Ah, [...] ficou bem complicado [...], ele ficou revoltado, até os médicos apanhavam dele na época, e daí elas diziam pra mim que aquilo ali era efeito das químicas, eu ficava machucada fisicamente e aqui também, sabe (coração)" (WF).
Chiattone (2003) acrescenta, portanto, que o sofrimento imposto pela doença só pode ser aliviado quando a criança entende o verdadeiro sentido do aparecimento de sua doença, da necessidade de hospitalização e dos procedimentos. Ela precisa ser vista, reconhecida e acolhida pelo olhar do outro - o olhar de sua família e dos profissionais que cuidam dela, para que possa, então, aceitar o seu corpo doente (D`Alcântara, 2008). Compreender a doença e aceita-la é, pois, fundamental para que a criança assim o faça e se reconheça apesar das marcas que o tratamento lhe confere.

\section{Perspectivas para o futuro}

Embora a doença somática seja uma lesão que, muitas vezes, se apresenta semelhante em diversos indivíduos, a mesma deve ser entendida de modo singular e particular para cada sujeito, ou seja, a forma como cada um se serve dela e resiste a ela é sempre pessoal e as reações diante dos diagnósticos são distintas nas diferentes pessoas (Fernandes, 2006). Alguns são mais passivos, depositam na fé ou no destino divino o ocorrido, outros são inconformados e negam ou se culpam pelo que aconteceu. São diversas as reações perante o diagnóstico de câncer, contudo, as expectativas de melhora ecoam esperança:

"Eu vejo andando de bicicleta, eu vejo $o H$. se graduando sabe, e eu tenho certeza que o que ele ta passando vai fazer dele um guri diferenciado, acho que a doença, tudo que ele tá passando, sabe, ele vai, ele é pequeno não vai lembrar de muita coisa, né, mas de alguma forma ele vai lembrar" (QF).

Portanto, "Talvez seja necessário usar o coração e todos os sentidos para o entendimento total desses seres humanos em formação, únicos e complexos, universos de necessidades e manifestações somáticas e emocionais intimamente ligadas e dependentes" (Barbosa, 1999, p. 2). Constata-se, ainda, que as perspectivas para o futuro apresentam-se repetidamente de melhoras, curas, cuidados, recuperações do tempo passado internado, enclausurados na insegurança de um tratamento que luta dia após 
dia com a doença. A saúde é hipervalorizada, os ideais de uma vida comum, com seus sonhos, conquistas é relatado, os planos de seguir o rumo natural das coisas sem ser interrompido pela drástica notícia do diagnóstico de câncer ganham ênfase nessa hora em que o olhar para o futuro se enche de esperança a fim de continuar de onde se parou, unir a família de novo, retomar as atividades cotidianas e, sobretudo, ter de volta a saúde do filho(a) que por hora esteve em "corda bamba", assim como os corações dos pais que tudo acompanharam. Força, saúde e valor à vida - o que se espera, o que se deseja, o que se sente no fim das contas:

"Eu vejo isso como um marco na vida dele, pra ele enfrentar as coisas com mais facilidade, pra ele não esquecer que em primeiro lugar ele é uma criança e tem um futuro, eu levo ele pra casa, ele tem que brincar [...]" (QF).

Assim, mesmo que a significação e a revelação do câncer ao filho perpassem, por questões acerca da castração provocada pela ausência, pelo conflito narcísico que um filho enfermo provoca em seus progenitores, pela ameaça de perda do filho, atrelando a doença ao mecanismo primeiro da negação, necessita-se, acima de tudo, de sensibilidade; eis um instrumento que deverá estar sempre presente entre aqueles utilizados do ambiente hospitalar. É ele que ajudará a perceber que, por trás de cada paciente, existe uma história; por trás de cada luta, um desejo, e, para além do desejo, existe vida.

\section{Considerações finais}

Mediante o adoecimento de uma criança por câncer, rápidas e intensas transformações se instalam no cotidiano familiar. Nesse momento o sofrimento toma conta da família que, envolta pelas fantasias que o diagnóstico oncológico traz, necessita apoiar e sustentar uma criança fragilizada pela doença e ainda lidar com as alterações emocionais e sociais que a cronicidade implica.

Os resultados do presente estudo confirmam as profundas ressonâncias familiares suscitadas pela enfermidade que acomete a criança e ratificam o processo do tratamento como uma fonte de tensão e estresse elevado para toda a família. O câncer infantil e seu tratamento têm, portanto um impacto sistêmico sobre a organização familiar, que a torna vulnerável ao sofrimento psíquico que atinge não apenas a criança, como também seus cuidadores. Dessa forma, esse sofrimento evidencia-se nas fantasias que perpassam desde a suspeita do diagnóstico até a confirmação do mesmo, pelas alterações e implicações profissionais e sociais, modificações e adaptações familiares, culpas, faltas, dores, mudanças físicas e expectativas para além da doença.

Entretanto, faz-se fundamental elucidar que, independentemente de sua idade e de sua capacidade de compreensão cognitiva da realidade que a circunda, a criança de algum modo se dá conta de que algo grave e temível está acontecendo consigo. E é nesse momento que a família, ou melhor, os pais, como mantenedores da sustentação egóica infantil e fonte de apego e afeto, ganham papel fundamental na elaboração de sua doença pela própria criança.

Assim, considerando que a vivência da doença se configura como uma situação de crise e reorganiza a dinâmica familiar, acredita-se que as reações emocionais intensas desencadeadas requerem acompanhamento psicológico sistemático para auxiliar os pais a conterem e a elaborarem as ansiedades vivenciadas nas situações que permeiam o processo de tratamento oncológico. Nesse sentido, cabe à Psicologia Hospitalar contribuir com espaços de escuta e acolhimento, disponibilizando programas de intervenção preventiva junto aos pais que acompanham o tratamento de seus filhos.

Faz-se necessário, então, que o psicólogo hospitalar amplie seu olhar sobre a clínica e os sujeitos implicados no adoecer, considerando a integralidade do cuidado em todas as etapas do tratamento. Trata-se de resgatar os aspectos saudáveis em meio à doença $\mathrm{e}$ propiciar alternativas para enfrentar a linha tênue que separa as melhoras das fraquezas, o saudável do enfermo, a vida da morte. 


\section{Natalia Schopf Frizzo}

Residente pela Universidade Federal de Santa Maria - RS. Brasil.

E-mail: nataliafzz@hotmail.com

\section{Alberto Manuel Quintana}

Doutor pela Universidade Federal de Santa Maria - RS. Brasil.

\section{Adelise Salvagni}

Mestranda pela Universidade Federal de Santa Maria - RS. Brasil.

\section{Ângela Barbieri}

Mestranda pela Universidade Federal de Santa Maria - RS. Brasil.

\section{Lenir Gebert}

Especialista pela Universidade Federal de Santa Maria - RS. Brasil.

\section{Endereço para envio de correspondência:}

Rua Conde de Porto Alegre, 953, apto. 803. Centro. CEP: 97015-110. Santa Maria RS. Brasil.

Recebido: 04/09/2013, $1^{\text {a }}$ Reformulação: 21/08/2014, Aprovado: 03/07/2015. 
Angerami-Camon, V. A. (1997). Psicologia hospitalar: teoria e prática. São Paulo, SP: Pioneira.

Barbosa, R. F. (1999). A dor de infância. In M. D. Moura (Ed.), Psicanálise e hospital: a criança e sua dor. Rio de Janeiro, RJ: Revinter.

Beck, A. R. M., \& Lopes, M. H. B. M. (2007). Cuidadores de crianças com câncer: aspectos da vida afetados pela atividade de cuidador. Revista Brasileira de Enfermagem, 60(6), 670-675. doi:10.1590/S0034-71672007000600010

Berlinck, M. T. (2000). Psicopatologia fundamental. São Paulo, SP: Escuta.

Cagnin, E. R. G., Liston, N. M., \& Dupas, G. (2004). Representação social da criança sobre o câncer. Revista da Escola de Enfermagem da USP, 38(1), 51-60. doi:10.1590/S0080-62342004000100007

Campos, C. J. G. (2004). Método de análise de conteúdo: ferramenta para a análise de dados qualitativos no campo da saúde. Revista Brasileira de Enfermagem, 57(5), 611-614. doi:10.1590/S0034-71672004000500019

Cardoso, F. T. (2007). Câncer infantil: aspectos emocionais e atuação do psicólogo. Revista da Sociedade Brasileira de Pesquisa Histórica, 10(1), 25-52.

Carter, B., \& McGoldrick, M. (2001). As mudanças do ciclo de vida familiar: uma estrutura para a terapia familiar. Porto Alegre, RS: Artes Médicas.

Casellato, G. (2002). Luta pela perda de um filho: a repercussão possível diante do tipo de perda. In M. H. P. Franco, Uma jornada sobre o luto: a morte e o luto sob diferentes olhares. Campinas, SP: Livro Pleno.

Castro, E. K., \& Piccinini, C. A. (2002). Implicações da doença orgânica crônica na infância para as relações familiares: algumas questões teóricas. Psicologia: Reflexão e Crítica, 15(3), 625-635. doi:10.1590/S0102-79722002000300016

Chiattone, H. B. C. (2003). A criança e a hospitalização. In V. A. Angerami-Camon (Ed.), A psicologia no hospital. São Paulo, SP: Pioneira.
Crepaldi, M. A. (1998). Famílias de crianças hospitalizadas: os efeitos da doença e internação. Revista Ciência e Saúde - Florianópolis, 17(1), 82-92.

D`Alcantara, E. B. (2008). Criança hospitalizada: o impacto do ambiente hospitalar no seu equilíbrio emocional. Revista Virtual de Psicologia Hospitalar e da Saúde, 3(6), 38-55.

Fernandes, M. H. (2006). Entre a alteridade e a ausência: o corpo em Freud e sua função na escuta do analista. In E. U. Cintra (Ed.), O corpo, o eu e o outro em psicanálise. Goiânia, GO: Dimensão.

Freud, S. [1996]. Luto e Melancolia. In: S. Freud, Edição standard brasileira das obras completas de Sigmund Freud (Vol. 19, pp. 243-263). Rio de Janeiro, RJ: Imago. (Trabalho original publicado em 1916).

Freud, S. [1990]. O ego e o id. In S. Freud, Edição standard brasileira das obras psicológicas completas de Sigmund Freud (Vol. 19, pp. 11-83). Rio de Janeiro, RJ: Imago. (Trabalho original publicado em 1923).

Freud, S. [1976]. Análise terminável e interminável. In S. Freud, Edição standard brasileira das obras psicológicas completas de Sigmund Freud (Vol. 23, pp. 247-88). Rio de Janeiro, RJ: Imago. (Trabalho original publicado em 1937).

Kovács, M. J. (1992). Morte e desenvolvimento humano. São Paulo, SP: Casa do Psicólogo.

Lacaz, C. P. (2003). Descortinando o universo: a família da criança com câncer. São Paulo, SP: Cabral.

Lima, R. A. G. (1995). A enfermagem na assistência à criança com câncer. São Paulo, $\mathrm{SP}: \mathrm{AB}$.

Marques, A. P. F. S. (2004). Câncer e estresse: um estudo sobre as crianças em tratamento quimioterápico. Psicologia Hospitalar, 2(2), 1-12.

Mazzora, L., \& Tinoco, V. (2005). Luto na infância: intervenções psicológicas em diferentes contextos. Campinas, SP: Livro Pleno.

Minayo, M. C. S. (2008). O desafio do conhecimento: pesquisa qualitativa em saúde (11a ed). São Paulo: Hucitec. 
Parkes, C. M. (1998). Luto: estudos sobre a perda na vida adulta (M. H. F. Bromberg, trad.). São Paulo, SP: Summus.

Patistea, E. (2005). Description and adequacy of parental coping behaviours in childhood leukaemia. International Journal of Nursing Studies, 42(3), 283-296. doi:10.1016/j.ijnurstu.2004.06.010

Pedrosa, A., Pedrosa, F., Pedrosa, T. F., \& Pedrosa, S. F. (2005). Comunicação do diagnóstico do câncer infantil. In E. Perina, As dimensões do cuidar em psicologia pediátrica. Campinas, SP: Livro Pleno.

Penna, T. L. M. (2004). Dinâmica psicossocial de famílias de pacientes com câncer. In F. Mello, \& B. Julio, Doença e família (23a ed.). São Paulo, SP: Casa do Psicólogo.

Quintana, A. M. (1999). Traumatismo e simbolização em pacientes com câncer de mama. Temas em Psicologia, 7(2), 107-18.

Ramalho, M. A. N. (2002). Psico-oncologia e luto: crianças com câncer. In M. H. P. Franco, Uma jornada sobre o luto: a morte e o luto sobre diferentes olhares. Campinas: Livro Pleno.

Santos, C. T., \& Sebastiani, W. R. (2003). Acompanhamento psicológico à pessoa portadora de doença crônica. In V. A. Angerami-Camon (Ed.), E a psicologia entrou no hospital. São Paulo, SP: Pioneira Thomson Learning.

Silva, C. N. (2000). Como o câncer (des) estrutura a família. São Paulo, SP: Annablume.

Silva, F. A. C., Andrade, P. R., Barbosa, T. R., Hoffmann, M. V., \& Macedo, C. R. (2009). Representação do processo de adoecimento de crianças e adolescentes oncológicos junto aos familiares. Revista de Enfermagem, 13(2), 334-41.

Silva, L. C., Weiss, E. M., Bernardes, D. B., \& Souza, A. I. J. (2006). Hospitalização e morte na infância: desafios das famílias. Família, Saúde e Desenvolvimento, 8(1), 73-79.

Souza, A. A. M., Lemos, M. H. M., Maia, R. C. S., Marques, A. P. M. L., \& Silva, J. R. (2010). A percepção da criança e do adolescente frente ao processo de hospitalização. Revista Multidisciplinar das Faculdades Integradas Pitágoras, 8(9), 4-11.

Teixeira, L. C. (2006). Um corpo que dói: considerações sobre a clínica psicanalítica dos fenômenos psicossomáticos. Latinamerican Journal of Fundamental Psychopathology, 6(1), 21-42.

Turato, E. R. (2003). Tratado da metodologia da pesquisa clínico-qualitativa: construção teórico-epistemológica, discussão comparada e aplicação nas áreas da saúde e humanas. Petrópolis, RJ: Vozes.

Valle, E. R. M. (1994). Vivências da família da criança com câncer. In M. M. M. J. Carvalho (Ed.), Introdução à psico-oncologia. São Paulo, SP: Psy II.

Valle, E. R. M. (1997). Câncer infantil: compreender e agir. Campinas, SP: Psy.

Valle, E. R. M. (2001). Psico-oncologia pediátrica. São Paulo, SP: Casa do Psicólogo.

Vieira, M. A., \& Lima, R. A. G. (2002). Crianças e adolescentescomdoençacrônica:convivendo com mudanças. Revista Latino-americana de Enfermagem, 10(4), 552-560. doi:10.1590/S0104-11692002000400013 